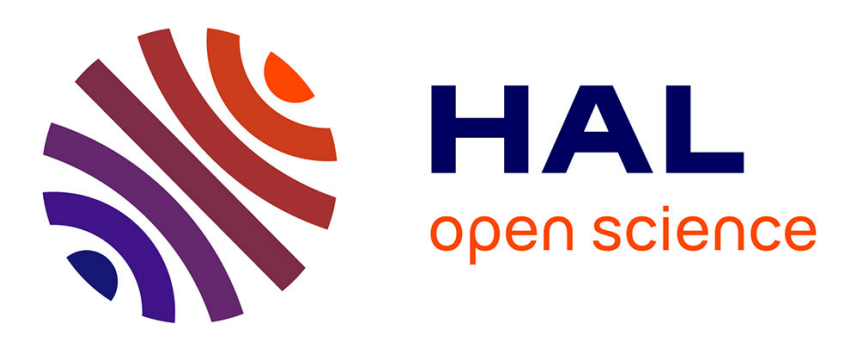

\title{
New characterisation method of electrical and electronic equipment wastes (WEEE)
}

\author{
Nour-Eddine Menad, Sylvain Guignot, Jan van Houwelingen
}

\section{To cite this version:}

Nour-Eddine Menad, Sylvain Guignot, Jan van Houwelingen. New characterisation method of electrical and electronic equipment wastes (WEEE). Waste Management, 2013, 33 (3), pp.706-713. 10.1016/j.wasman.2012.04.007 . hal-01017115

\section{HAL Id: hal-01017115 https://hal-brgm.archives-ouvertes.fr/hal-01017115}

Submitted on 15 Jul 2014

HAL is a multi-disciplinary open access archive for the deposit and dissemination of scientific research documents, whether they are published or not. The documents may come from teaching and research institutions in France or abroad, or from public or private research centers.
L'archive ouverte pluridisciplinaire HAL, est destinée au dépôt et à la diffusion de documents scientifiques de niveau recherche, publiés ou non, émanant des établissements d'enseignement et de recherche français ou étrangers, des laboratoires publics ou privés. 


\title{
NEW CHARACTERISATION METHOD OF ELECTRICAL AND ELECTRONIC EQUIPMENT WASTES (WEEE)
}

\author{
N. Menad"*, S. Guignot" and J.A. van Houwelingen ${ }^{* *}$ \\ *BRGM, 3 av. C. Guillemin, 45060 Orléans, FRANCE \\ ${ }^{* *}$ Recycling Consult, Eindhoven, NETHERLANDS, recy.cling@,iae.nl \\ Corresponding author. Mail: n.menad@,brgm.fr
}




\section{Abstract}

Innovative separation and beneficiation techniques of various materials encountered in Electrical and Electronic Equipment Wastes (WEEE) is a major improvement for its recycling. Mechanical separation-oriented characterization of WEEE was conducted in an attempt to evaluate the amenability of mechanical separation processes. Properties such as liberation degree of fractions (plastics, metals ferrous and non-ferrous), which are essential for mechanical separation, are analysed by means of a grain counting approach. Two different samples from different recycling industries were characterised in this work. The first sample is a heterogeneous material containing different types of plastics, metals (ferrous and nonferrous), Printed Circuit Board (PCB), rubber and wood. The second sample contains a mixture of mainly plastics. It is found for the first sample that all aluminium particles are free $(100 \%)$ in all investigated size fractions. Between 92 and $95 \%$ of plastics are present as free particles; however, $67 \%$ in average of ferromagnetic particles are liberated. It can be observed that only $42 \%$ of ferromagnetic particles are free in the size fraction larger than $20 \mathrm{~mm}$. Particle shapes were also quantified manually particle by particle. The results show that the particle shapes as a result of shredding, turn out to be heterogeneous, thereby complicating mechanical separation processes. In addition, the separability of various materials was ascertained by a sink-float analysis and eddy current separation. The second sample was separated by automatic sensor sorting in four different products: ABS, PC-ABS, PS and rest product. The fractions were characterised by using the methodology described in this paper. The results show that the grade and liberation degree of the plastic products ABS, PC-ABS and PS are close to $100 \%$. Sink-float separation and infrared plastic identification equipment confirms the high plastic quality. On the basis of these findings, a global separation flow sheet is proposed to improve the plastic separation of WEEE. 


\section{Introduction}

WEEE needs increasing Reuse, Recycling and Recovery (3R). In Europe, the amount of WEEE generated is 12 million ton per year (Lehtinen, U., Poikela, K. 2006). Only 2.2 million ton is treated representing about 18\% (Government gazette, 2011). The end of life equipment contains hazardous materials such as PCB (PolyChloroBiphenyl), cadmium and mercury. It also contains valuable materials such as ferrous and non-ferrous metals, engineering plastics, precious metals, platinum group metals and rare earths elements. WEEE will increase in the coming decades with an expected rate of at least $4 \%$ per year, about three times higher than the growth of the average municipal waste (Gramatyka et al, 2007). Much of WEEE is exported to Africa, China and India and disassembled under inadequate working conditions (Bastiaan C et al, 2010). More than 78\% of European WEEE is currently land filled or incinerated (Government gazette, 2011). This publication will demonstrate improved re-use, recycling and recovery (3R) through better size reduction, smart sensor sorting and advanced density separation.

WEEE contains a large amount of different engineering plastics that need further separation with advanced separation techniques in order to produce high added value plastics. WEEE also contains the recoverable metals such as, aluminium, copper, lead, zinc, metals alloys, precious metals (gold and silver), and platinum group metals, and rare earth elements which are currently hardly recycled (Sm, Eu, Y, Gd and Dy) (Menad and van Houwelingen, 2011). The prices of these metals are expected to increase by $15 \%$ annually due to increased demand, quotas, supply shortages and limited numbers of suppliers (Government gazette, 2011). In order to develop and implement both environmentally friendly and economically viable recycling processes, in-depth characterization of this specific material stream, oriented towards mechanical separation amenability, is necessary. It has been demonstrated that it is valuable to recycle WEEE in spite of the fact that the content of precious metals $(\mathrm{Au}, \mathrm{Ag}, \mathrm{Pd})$ 
gradually decreases. Alternatively, a full material recovery involving ferromagnetic, nonferrous metals, precious metals and non-metallic, through mechanical separation, may be applicable both economically and technically.

Mechanical separation-oriented characterization is studied of two samples provided by recycling industries: a heterogeneous sample S1 and a plastic sample S2. The characterization consisted of determination of the composition, the particle size distribution, the degree of liberation through a particle counting, particle shape quantification, plastic identification by a hand held detector based on infrared (IR) spectroscopy and a separability investigation through a sink-float analysis, magnetic and eddy current separation. The identification of flame retardants in the plastics was carried out with a hand held X-ray fluorescence (XRF) device.

\section{Materials and procedure}

\subsection{Materials}

Two different samples are provided by WEEE processing plants, S1 and S2. For the first sample the input consists of category 2, 4 and 6 of the WEEE Directive 2002/96/EC of 27 January 2003. A sample of $100 \mathrm{~kg}$ was taken after shredding with a hammer mill with a slotted discharge opening of $100 \mathrm{X} 60 \mathrm{~mm}$. This sample is very heterogeneous containing plastics, electric wires, wood and ferrous and non-ferrous metals. Sample S2 contains different types of plastics from WEEE obtained through disassembly of pc-monitors. A big bag of S2 was shredded with a slow rotating shearing type shredder. S2 was characterized and as part of the analyses separated by automatic sensor sorting in four different fractions: ABS, PC-ABS, PS and a rest product.

\subsection{Procedure}

The methodology of characterisation used in this investigation is given in Fig. 1. The sampled materials are screened. The size fractions obtained are characterised by the following steps: 
1. Determination of colour, particle shape and liberation degree.

2. The plastic type is identified by IR and the flame retardant elements in the plastic by XRF hand held instruments. The density is determined by using sink float analysis.

3. Ferrous and non-ferrous metals are quantified by using magnetic and eddy current separators respectively.

Fig. 1

\subsubsection{Composition}

The composition is determined by manual sorting supported by a hand magnet, a hand held IR device and a hand held XRF device. Shredded WEEE in general consists of ferrous and nonferrous metals, plastics, printed circuit boards, glass, cable, paper and wood, which are easily recognized. The composition determines the material flows when separated after shredding.

\subsubsection{Particle size distribution}

The particle size distribution (PSD) was determined by screening. Sample S1 was classified into the fractions $+2,2-10,10-20$ and $+20 \mathrm{~mm}$. Sample S2 (plastics) is classified into $+5,5$ $10,10-20$, and $+20 \mathrm{~mm}$. The products obtained from each size fraction are subjected to characterisation using the steps shown in Fig.1. Different shredding methods are of influence to the PSD and subsequent separation options.

\subsubsection{Shape factor quantification}

The identification and quantification of different particle shapes of the investigated samples was performed manually. The quantitative criterion is expressed in terms of $F$-Shape given as follow:

$$
\mathrm{F}-\text { Shape }=\mathrm{D}_{\min } / \mathrm{D}_{\max }
$$


Where $\mathrm{D}_{\max }$ is defined as the longest diameter of one particle obtained by selecting the largest of the Ferret diameters, and $\mathrm{D}_{\text {min }}$ represents the shortest among samples Ferret diameters. According to this definition a sphere has a shape factor of 1. Since particles after shredding have irregular shapes, the shape factor will be far lower than 1 . Ferrous metals often appear as sheet metal or as strip, disc or axle, copper as wire and plastics as a plate shaped material or foil. The shape factor then is lower than 1. In case of plastic foils, the factor can be lower than 0.01 . After mild shredding without a discharge, grid the shape factor is smaller than after shredding with a discharge grid. Repeated shredding with smaller discharge openings will cause the shape factor of materials to converge to 1. Material handling, sorting and separation will be facilitated by more uniform particles

\subsubsection{Colour identification}

The colour determination of the plastic particles was made visually. The colours red, black, grey and yellow are found. The plastics with the same colour are weighed separately and the weight $\%$ was calculated for each fraction. The colour of plastics is an important property for sorting. Black plastics are currently recognized by FTIR (a slow laboratory analyses) and not by fast IR sensors, maybe in future a method is found for sorting. The coloured plastics can be sorted by fast NIR in their various polymer types. Additives like flame retardants (bromine, phosphor, antimony) or pigments are recognized by XRF in coloured and black plastics. For the recycler the possibility is open to apply selective sorting into coloured and black housing for instance of monitors or TVs respectively. Sensor sorting devices often are equipped with an IR sensor and a colour sensor combined.

\subsubsection{Liberation degree determination}

The liberation of different materials after size reduction of WEEE is essential for separation. The liberation of this material is relatively large after the first shredding. A proven and simple 
method to quantify the liberation degree is counting the liberated and non-liberated particles of the sample using the following equation.

$$
\mathrm{LD}=\sum_{\mathrm{i}=1}^{\mathrm{N}} \frac{\mathrm{N}_{\mathrm{fi}}}{\mathrm{N}_{\mathrm{fi}}+\mathrm{N}_{\mathrm{li}}} / \mathrm{N}
$$

Where, $L D$ denotes the mean liberation degree, $\mathrm{N}$ is the number of the counted samples, and $N_{f i}$ indicates the locked particles of the same material in the $i t h$ sample. In the present investigation two different samples of $2 \mathrm{~kg}$ were analysed and the liberation degree was calculated according to this equation.

\subsubsection{Determination of plastic density by sink-float distribution}

The determination of the density with heavy liquids is a method to sort plastic types into density classes. This method is extensively utilized to characterize the density of plastics. The heterogeneity of materials and the difference in density makes dry or wet separation processes efficient, economically viable and environmentally friendly.

A substantial share of the materials in electronic scrap consist is plastics with a density generally lower than $2.0 \mathrm{~g} / \mathrm{cm}^{3}$. Characterization by density separation was conducted. The floats and the final sinks are weighed. In addition IR plastic detection was used to determine the plastic types.

Density separation is presently the most practised method to recover plastics from WEEE. However, the density classes produced still contain different types of plastics. Various densities overlap which are the result of additives like flame retardants, fillers and different plastic types (Kobler and Foss, 2004). As shown in Fig.2, the brominated, phosphated, and ABS-PVC flame retardant families are found overlapping in the 1.16 to 1.25 density range. Fig. 2

\subsubsection{Plastics identification with NIR and XRF}


WEEE contains several types of plastics which are difficult to identify visually. Recently, new equipment based on Near Infra-Red (NIR) spectroscopy was developed for this purpose. Plastics obtained from the size fractions of $20 \mathrm{~mm},-20 / 10 \mathrm{~mm}$ and $-10 / 2 \mathrm{~mm}$ were analysed. The identification of flame retardants was performed by using a hand held XRF device. The XRF analyser quantifies the halogen elements contained in the plastic. The identification of plastic with IR is only possible if the plastic is not black or coloured. Automatic mechanical sensor sorting becomes available with modern fast and smart sensor sorting equipment based on IR.

The IR plastic detector (Fig.3) is developed by Polychromix and is using the micro-electromechanical-system (MEMS) permitting the assembly of a spectrometer without mobile parts and a low energy consumption. These characteristics are ideal for the manufacture of portable hand held instruments.

The hand held XRF device operates on the principle of X-ray fluorescence, which uses X-rays to excite the atoms in a sample and measures the fluorescent X-rays re-emitted by the material. The analyser rapidly determines the elements present as well as their relative concentrations. For samples with known ranges of chemical composition, such as common grades of metal alloys, the analyser can also rapidly identify most sample types. The instrument is valuable for a wide range of applications, including scrap recycling, PMI (Positive Material Identification), metal fabrication, electronic component testing, solder analysis, lead paint testing, RoHS and WEEE compliance.

Fig. 3

\subsubsection{Ferrous and non-ferrous metals quantification}

Ferrous metals are recovered by magnetic separation. Different methods are applied. The industry mostly is equipped with cross belt electro magnets. The magnet is positioned across the conveyor belt. The distance of the magnet to the belt is of influence for the composition of 
the magnetic fraction. Also head pulley magnets are used. Ferrous materials recovered consist of iron, galvanized and tin coated steel, ceramic ferrites and magnet material (motors, coils, transformers). Some stainless steel alloys are weakly magnetic, some are non-magnetic. The organisation of magnetic separation throughout the WEEE processing plant decides the recovery of ferrous metals and its grades.

Eddy current separation is used in the recycling industries for the recovery of non-ferrous metals from end-of-life vehicles (ELV), electrical and electronic waste (WEEE), construction and demolition waste (C\&DW), municipal solid waste incinerator bottom ashes (MSWI) and municipal solid waste (MSW) (Veasey et al, 1993). The principle of eddy current separation is based on an alternating magnetic field that is inducing a force on a conductor causing it to be deflected from non-conductors (Fig. 4). The repulsion force in combination with the product belt speed and the optimization of the product splitter plate provides a means for the effective separation. A rapidly rotating magnetic drum is positioned inside a non-metallic drum which rotates with the conveyor belt speed. The metal particles mostly have an irregular shape which causes an irregular force and deflection. Eddy current separation is used to separate non-ferrous metals $(>2 \mathrm{~mm})$ from plastic materials. Fig. 4 shows the eddy current separator used in this study (left) and a cross section of the separation principle. Occasionally ferrous materials are separated into a magnetic fraction mainly consisting of small particles that are not catched in previous magnetic separation.

Fig. 4

Eddy current metal concentrates area further processed by a sink-float plant to separate aluminium from copper and other metals. Copper based metal concentrates are sold to metallurgy for copper recovery by smelting and refining. Aluminium is sold to secondary aluminium smelters. A careful recipe of scrap with pure aluminium is required to produce specific alloys. The concentrate of printed circuit boards produced in WEEE scrap processing 
plants is sold to copper metallurgy. Concentrates are sampled and assayed by a surveyor, the sample is crushed, the polymer part is incinerated. The remaining part (metals and inerts) is melted together with fluxes and a fixed amount of aluminium as a collector of metals. After solidification the separated metal phase and slag phase are analysed by XRF for the presence of $\mathrm{Cu}, \mathrm{Au}, \mathrm{Ag}, \mathrm{Pd}$ and other elements of interest. The seller and buyer make up a contract and the payment is made according to the formula (P.J. Lewis, C.G. Streets, 1978):

Smelter Value $=(M-U D) *(P-R C)-T C-X+Y$

where $\mathrm{M}$ is the $\mathrm{Cu}$ concentrate in percentage; UD the unit deduction (set by smelter) in percentage, mostly 1-2\%; P the copper notation at London Metal Exchange (LME); RC the refining charge; TC the treatment charge; $X$ the penalties for elements over a threshold value; $\mathrm{Y}$ is the payments for $\mathrm{Au}, \mathrm{Ag}, \mathrm{Pd}$ (with their specific refining cost, unit deductions).

\section{Results and discussion}

Two different samples from different recycling industries are characterised. Sample S1 is a heterogeneous material containing different types of plastics, metals (ferrous and nonferrous), printed circuit boards (PCB), rubber, wood, etc. (fig.5). Sample S2 contains mostly plastics with high content of ABS (fig.6).

Fig.5

Fig.6

\subsection{Composition of the samples $S 1$ and $S 2$}

Table 1 shows the composition of both samples. $64 \%$ of $\mathrm{S} 1$ is $+20 \mathrm{~mm}$, containing $33 \%$ plastics, $8 \%$ electric wires, $7.7 \%$ ferrous materials, $10 \%$ non-ferrous metals and $2.4 \%$ PCBs. The size fraction $+10 \mathrm{~mm}$ representing $19 \%$ contains $10 \%$ plastics, $4 \%$ ferrous materials, electric wires $(0.5 \%), 2 \%$ non-ferrous metals and others $(1.8 \%)$. Fraction $2-10 \mathrm{~mm}(12.4 \%)$ 
contains mostly plastics $(6.8 \%)$ and some metals (1.9\%). The fraction $<2 \mathrm{~mm}(4.7 \%)$ contains only fines (4\%).

S2 contains mostly plastics. $97 \%$ is present in the fraction $+20 \mathrm{~mm}$ containing around $95 \%$ plastics, $0.6 \%$ PCB and $0.8 \%$ others. The fractions $+10 \mathrm{~mm}$ and $5-10 \mathrm{~mm}$ represent respectively, $2 \%, 0.3 \%$. These fractions contain mostly plastics.

Table 1

\subsection{Particle size distribution}

The PSD is presented in Fig. 7 where the cumulative wt $\%$ against the particle diameters of both samples is summarised. It can be seen that the $\mathrm{d} 90$ of $\mathrm{S} 1$ is close to $5 \mathrm{~mm}$ and more than $95 \%$ of $\mathrm{S} 2$ consists of particles $+20 \mathrm{~mm}$ and containing mostly plastics. The difference in PSD for S1 and S2 is caused by a different type of shredder. For S1 a fast rotating hammer mill was used with a fixed grid and for S2 a slow rotating shear shredder.

Fig. 7

\subsection{Particle shape}

The particle shape characterisation is very important because it has an effect on the separation processes. It is well-known that diversified shapes have a market impact on materials handling. The sample S1 which is heterogeneous material was subjected to determination of F-shapes for each particle. The results show that the Factor-shape of the investigated particles is less than of 0.7 (1.0 is equal to a sphere). This indicates that most particles have a rectangular form.

\subsection{Colour identification}

The identification of colour of different size fractions containing plastics was done visually particle by particle. It can be noted that the grey, white and black colours are predominant in these plastics. Other colours such as red, blue and green were found in small percentages.

\subsection{Liberation degree}


The liberation degree method was performed on S1 containing free and non-free particles. Using the equation (2), the liberation degree of ferromagnetic, $\mathrm{Al}, \mathrm{Cu}$ and plastics in the sample S1 are grouped in Table 2.

Table 2

All aluminium particles are free (100\%) in the four size fractions. Between 92 and $95 \%$ of plastics are present as free particles; however $67 \%$ and $52 \%$ in average of ferromagnetic and copper particles are liberated respectively. It can be observed that only $42 \%$ of ferromagnetic particles are free in the size fraction $20 \mathrm{~mm}$.

\subsection{Curve of specific density}

A density distribution of the plastics is acquired with a range of denser fluids starting with water. Different salts can be used to dissolve in water to reach the required density classes. Figure 8 shows the cumulative wt $\%$ float and sink of plastics from $\mathrm{S} 1$ plotted against the density of separation. It is shown that more than $60 \%$ of plastics float at $1.2 \mathrm{~g} / \mathrm{cm}^{3}$ and about $85 \%$ has a density higher than $1.1 \mathrm{~g} / \mathrm{cm}^{3}$.

Fig. 8

\subsection{Plastics quantification}

The characterization of plastic types was performed on sample S1 with a combination of sink float separation and NIR plastic detection. The results show that the plastics present in S1 with size fraction $+20 \mathrm{~mm}$ contain more than $38 \%$ ABS and most of them have a density of $1.0-1.1 \mathrm{~g} / \mathrm{cm}^{3}$. The plastic composite ABS/PA/PC is mostly present in the size fraction of $10-$ $20 \mathrm{~mm}$ with a density of $1.19-1.31 \mathrm{~g} / \mathrm{cm}^{3}$. The three investigated size fractions $(+20 \mathrm{~mm},-$ $20 / 10 \mathrm{~mm}$ and $-10 / 2 \mathrm{~mm}$ ) contain respectively $35 \%, 53 \%$ and $50 \%$ of black plastics which are not identified with NIR. PVC is less present in S1 $(1.6 \%$ at $+20 \mathrm{~mm}$ and $1.2 \%$ at $-10 / 2 \mathrm{~mm})$. About $1.7 \%$ of PET plastics are detected in the size fraction of $-10 / 2 \mathrm{~mm}$. The polycarbonate plastics are detected in all fractions $(6 \%, 2 \%$ and $2 \%)$. 


\subsection{Quantification of plastics treated with flame retardant}

Plastics with flame retardant (FR), such as ABS, ABS/PA/PC, ABS/PC and black plastics were analysed with the XRF hand held analyser. The element bromine was detected in different types of plastics. The results for bromine can be checked against those of antimony since the two are always found together. The presence of antimony follows that of the bromine element. The results obtained show that $80 \%$ of ABS contains FR. ABS/PC and black plastics are only partly treated with FR. Some of them are completely treated with FR.

\subsection{Eddy current separation}

The optimisation of the eddy current separator was carried out by testing the pure mixture of aluminium and plastics with different forms and particle sizes. The following parameters were varied: particle size of feed material, speed of shell, conductivity, and position of splitter blade. S1 and S2 were subjected to this technique to recover the non-ferrous metals. The results show:

\section{For sample S1}

The raw material of $\mathrm{S} 1$ was screened in the following size fractions: $+40 \mathrm{~mm},-40+20 \mathrm{~mm}$, $20+10 \mathrm{~mm}$ and $-10 \mathrm{~mm}$. These fractions were subjected to separation by using magnetic and eddy current separation considering the optimal parameters. The results obtained from these separations and the recovery rates of ferrous, non-ferrous, plastics, dust foams and printed circuit boards (PCB) from S1 are presented in Table 3.

The magnetic fractions obtained from each size fraction are not clean except for the coarse fraction. This is due to the presence of particles of metals mixed with non-magnetic particles (plastics, ceramics etc.). It can also be seen that most plastics and non-ferrous (aluminium, copper, lead) are recovered in the non-conductor and conductor fractions respectively. From Table 3, it can be seen that the recovery rates of plastics are important in the fractions of 20-40 $\mathrm{mm}$ and 10-20 $\mathrm{mm}$ with less ferrous products (3 and 6\% respectively). 


\section{Table 3}

Therefore the printed circuit boards are only present in these fractions. About $15 \%$ and $11 \%$ of ferrous can be recovered from the coarse and fine fractions respectively. It is important to underline that all foamed products may be recovered from the fine fractions $(23 \%)$. From these tests, the following characterisation of the sample S1 may be estimated: $8 \%$ ferrous, $8 \%$ of non-ferrous, $79 \%$ plastics, $4 \%$ foam and $1.3 \%$ PCB.

\section{Sample $S 2$}

The sample was sorted by magnetic and eddy current separators. The results show that the magnetic fractions of the investigated size fractions are not clean, the recovery rate of these products ranges from 50 to $63 \%$ for the fractions $-10,10-20$ and $20-40 \mathrm{~mm}$. However, it is about $85 \%$ in the coarse fraction $(40 \mathrm{~mm})$. This is due to presence of free scrap particles in this fraction. On the other hand, the non-conductor fractions are mostly clean where the recovery rate of plastics is higher than $95 \%$ in all fractions. The quantity of non-ferrous products is very low, this is confirmed by eddy current separation, where the only coarse fraction $(40 \mathrm{~mm})$ constitutes about $1 \%$. Table 4 shows that $56 \%$ of S2 have particle size of $20-40 \mathrm{~mm}$, and between $85 \%$ and $99 \%$ of plastics can be recovered from all fractions.

\section{Table 4}

It can also be seen that only the coarse fraction contains non-ferrous. Other products like ceramics, wood and pieces of glass are present in these fractions $(0.5-3 \%)$. Most of ferrous particles are present in the coarse fraction $(40 \mathrm{~mm})$, and about $1-3 \%$ in other fractions. From these tests, the following characterisation of $\mathrm{S} 2$ is calculated: $4 \%$ ferrous, $0.2 \%$ non-ferrous, $93 \%$ plastics and $2.0 \%$ others.

S2 was sorted by an industrial scale NIR sensor separator and the produced plastic fractions ABS, PC-ABS, PS and a rest fraction were characterised according to the steps shown in Fig. 
1. The plastics contained in the sorted fractions ABS, PC-ABS, PS and a rest product are checked and identified by a hand held NIR device. The results are shown in Table 5. Table 5

The PC-ABS fraction contains about 89\% PC-ABS, 7.5\% PC and 2\% ABS in the size fractions $+20 \mathrm{~mm}$ and $10-20 \mathrm{~mm}$. This sample contains $0.2 \%$ not identified plastics and $1 \%$ other materials. Phazir plastic detector confirms the purity of the two first sorted samples, ABS sample (94-96\%) and PC-ABS (89\%). However, the PS plastic sample is not pure and contains $74 \%$ PS, $21 \%$ ABS, $2 \%$ PC-ABS and $2 \%$ not identified plastics. The size fraction of $20 \mathrm{~mm}$ is constituted on $67 \% \mathrm{ABS}$ and about $72 \% \mathrm{ABS}$ are found in the size fraction of 10 $\mathrm{mm}$ in the rest product. Less non-identify plastics (almost black) are present in this size fraction. About 10\% PS as well as PC-ABS are representing in both size fractions of the rest product.

According to the characterisation results of the investigated samples, the flow sheet given in Fig.9 is suggested to recover all components contained in electric and electronic wastes with high quality.

\section{Conclusions}

The WEEE samples S1 and S2 were characterised by using the methodology developed by BRGM and Recycling Consult. The techniques used are: classification in three size fractions, determination of composition, liberation degree, colour, shape factor, sink float analysis and identification of plastic types followed by determination of flame retardant containing in the plastics by using a hand held NIR device and a hand held XRF device. Separation of ferrous and non-ferrous metals was made by magnetic and eddy current separators. S2 was subjected to a commercial NIR sensor sorter. From this investigation, it can be concluded that: 
1. The analyses approach for WEEE samples proved valuable. The analyses were split between laboratory analyses and separation with commercial equipment. The results are combined and checked with hand held devices.

2. More than $60 \%$ of $\mathrm{S} 1$ is larger than $20 \mathrm{~mm}$. It contains more than $50 \%$ plastics which are predominantly in the size fraction $+20 \mathrm{~mm}$. The printed circuit boards represent about 5\% and most of them are in the coarse fraction. The characterisation shows more than $12 \%$ ferrous metals, and most of them are in the coarse fractions. The same estimation is made for non-ferrous materials. This sample contains around $5 \%$ fine particles $(-2 \mathrm{~mm})$. The majority of electric wires are concentrated in the size fraction $+20 \mathrm{~mm}(8 \%)$.

3. S2 contains mostly plastics. About $97 \%$ of the sample is present in the size fraction $+20 \mathrm{~mm}$ containing around 95\% plastics, $0.6 \%$ PCB (printed circuit board) and $0.8 \%$ others. The size fractions of $10 \mathrm{~mm}$ and $5 \mathrm{~mm}$ represent respectively $2 \%, 0.3 \%$ of the sample. These fractions contain mostly plastics. These fractions contain mostly plastics. Separation is conducted with a commercial sensor sorter. High recoveries and grades are achieved for ABS and PC-ABS.

4. Black plastics are not detected by NIR to determine the type.

\section{Acknowledgement}

The authors would like to acknowledge the European Executive Agency for Competitiveness \& Innovation (EACI) for financial support and giving us the possibility to work on this project. The authors would also like to express their appreciation for helpful discussions within the working group and all companies involved (PROMIKRON, PHB-Waalwijk and DOLPHIN Metal Separation) for providing input materials. 


\section{References}

Gramatyka, P., Nowosielski, R., Sakiiewicz, P., 2007. Recycling of waste electric and electronic equipment. Journal of Achievements in Materials and Manufacturing Engineering, 20, 1-2.

Government gazette, February 2011, http://governmentgazette.eu/wpcontent/uploads/2011/02/Government $\% 20$ Gazette $\% 20-020 \mathrm{Feb} \% 202011 . \mathrm{pdf}$

Kobler, R., Foss, H., 2004. Successful recovery of end of life electronics plastics using RPI's skin flotation technology. Recovery Plastics International (RPI), GPEC 2004 Paper Abstract \#32.

Lehtinen, U.; Poikela, K. September 2006. Challenges of WEEE on Reverse Logistics: A Case Study on a Collection Network in Finland. Proceedings of the Logistics Research Network Conference, Newcastle, UK.

Lewis, P.J., Streets, C.G., 1978. An analyses of Base-metal smelter terms. In: Jones, M.J. (Ed.), Proceedings of the 11th Commonwealth Mining and Metallurgical Congress, Hong Kong, pp 753-767.

Menad, N., van Houwelingen, J.A., 2011. Identification and recovery of rare metals in electrical and electronic scrap. Thirteenth International Waste Management and Landfill Symposium, S. Margherita di Pula (Cagliari), Sardinia, Italy.

Veasey, T., Wilson, R.J., Squires, D.M., 1993. Physical separation and recovery of metals from wastes. Taylor \& Francis.

Zoeteman, Bastiaan C. J., Krikke Harold R., Venselaar, Jan, 2010. Handling WEEE waste flows on the effectiveness of producer responsibility in a globalizing world. International Journal of Advanced Manufacturing Technology 47, 415-436. 